\title{
Growth inhibition effects of ent-11 $\alpha$-hydroxy-15-oxo-kaur-16-en-19-oic-acid on colorectal carcinoma cells and colon carcinoma-bearing mice
}

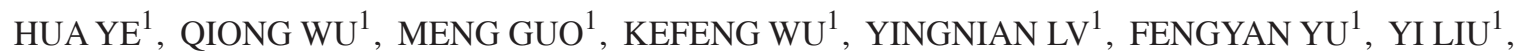 \\ XIAOSHENG GAO ${ }^{1}$, YUZHEN ZHU ${ }^{1}$, LIAO CUI ${ }^{1}$, NIANCI LIANG ${ }^{1}$, TU YUN ${ }^{2}$, LI LI $^{1}$ and XUEBAO ZHENG \\ ${ }^{1}$ Guangdong Key Laboratory for Research and Development of Natural Drugs, Guangdong Medical College; \\ ${ }^{2}$ Central People's Hospital of Zhanjiang, Zhanjiang, Guangdong 524023, P.R. China
}

Received March 12, 2015; Accepted November 17, 2015

DOI: $10.3892 / \mathrm{mmr} .2016 .4950$

\begin{abstract}
The aim of the present study was to investigate the mechanism underlying the antitumor effects of ent-11 $\alpha$-hydroxy-15-oxo-kaur-16-en-19-oic-acid (5F) in colorectal cancer (CRC). $5 \mathrm{~F}$ was isolated and used to treat C26 murine colon carcinoma cells, a xenograft tumor mouse model (induced by C26 cells) and a CRC mouse model [induced by 1,2-dimethylhydrazine (DMH)/dextran sodium sulfate (DSS)]. C26 cell growth was inhibited by $5 \mathrm{~F}$ in a dose- and time-dependent manner in vitro. In addition, $5 \mathrm{~F}$ induced cell apoptosis and cell cycle arrest in the $\mathrm{G}_{2}$ phase, increased the activity of caspase- 3 and caspase-9, but did not affect the activity of cascase- 8 , suggesting that $5 \mathrm{~F}$ induced apoptosis via activation of the mitochondrial signaling pathway rather than the death-receptor signaling pathway. Furthermore, treatment of C26 cells with 5F resulted in upregulation of cyclin-dependent kinase inhibitor 1A (p21, Cip1), $\mathrm{Bcl}-2$-associated $\mathrm{X}$ protein, nuclear factor of $\kappa$ light polypeptide gene enhancer in B-cells inhibitor, $\alpha$ and downregulation of B-cell lymphoma 2, nuclear factor $\kappa$-light-chain enhancer of activated B cells and survivin. In vivo animal models demonstrated that $5 \mathrm{~F}$ treatment protected mice from carcinogenesis induced by DMH/DSS and markedly decreased the xenograft tumor weight with minimal side effects. Therefore, 5F may have potential as an anti-CRC therapeutic agent for use in the clinical setting.
\end{abstract}

Correspondence to: $\mathrm{Dr} \mathrm{Li} \mathrm{Li}$ or Professor Xuebao Zheng, Guangdong Key Laboratory for Research and Development of Natural Drugs, Guangdong Medical College, 2 East Wenming Road, Zhanjiang, Guangdong 524023, P.R. China

E-mail: 1ili1918@yeah.net

E-mail: gy523024@163.com

Key words: colorectal cancer, cell apoptosis, mitochondrial pathway, xenograft

\section{Introduction}

Colorectal cancer (CRC) is the third most commonly diagnosed type of cancer worldwide (1), and is ranked the sixth and fifth in prevalence and mortality, respectively in China (2). In 2010, it was estimated that 274,841 new cases were diagnosed in China and 132,110 cases resulted in CRC-associated mortality (2). Despite significant advances in early diagnosis and therapy, the prognosis of CRC remains poor. Thus, development of effective and safe therapeutic strategies for CRC is required.

Ent-11 $\alpha$-hydroxy-15-oxo-kaur-16-en-19-oic-acid (5F) is isolated from a traditional Chinese herb, Pteris semipinnata L. (PsL). It has been demonstrated to kill various human cancer cells, such as nasopharyngeal carcinoma, lung cancer, laryngeal cancer, thyroid carcinoma, gastric cancer and colorectal cancer cells, in vitro by inducing apoptosis (3-8). Previous studies in mice also demonstrated that $5 \mathrm{~F}$ is effective against liver and lung cancer with minimal side effects $(9,10)$. Few previous studies have investigated treatment of CRC via $5 \mathrm{~F}$-induced apoptosis. Therefore, the present study aimed to examine the antitumor effect of $5 \mathrm{~F}$ in vitro and in vivo using CRC cells and two CRC mouse models, respectively.

\section{Materials and methods}

Cell culture. The C26 murine colon carcinoma cell line was obtained from Peking Union Medical College (Beijing, China). C26 cells were cultured in RPMI-1640 medium (Sigma-Aldrich, St. Louis, MO, USA) containing 10\% fetal bovine serum (Hyclone; GE Healthcare Life Sciences, Logan, UT, USA), $100 \mathrm{U} / \mathrm{ml}$ penicillin and $100 \mu \mathrm{g} / \mathrm{ml}$ streptomycin (both from Beyotime Institute of Biotechnology, Haimen, China). Cells were cultured at $37^{\circ} \mathrm{C}$ in $5 \% \mathrm{CO}_{2}$.

Cell proliferation assays. The 5F was isolated from $\mathrm{PsL}$ (Qingping Medicine Market, Guangzhou, China) as previously described (11), dissolved in propylene glycol (Sigma-Aldrich) and diluted immediately prior to use. C26 cells $\left(5 \times 10^{3}\right.$ cells/well $)$ were seeded in a 96 -well plate in $200 \mu \mathrm{l}$ RPMI-1640 medium. Following culture for $24 \mathrm{~h}$, the 
cells were exposed to $0,5,10,20,40$ or $80 \mu \mathrm{g} / \mathrm{ml} 5 \mathrm{~F}$. Cell viability was examined at 24,48 or $72 \mathrm{~h}$ using the MTT assay (Sigma-Aldrich) and expressed as a percentage of the control cells. The morphology of the cells was observed at $24 \mathrm{~h}$ under an inverted phase contrast microscope (CKX31-A12PHP; Olympus, Tokyo, Japan).

Cell cycle distribution. $\mathrm{C} 26$ cells were seeded at a density of $1 \times 10^{5}$ cells/well in a 6 -well plate. The cells were treated with 0 , $5,10,20$ or $40 \mu \mathrm{g} / \mathrm{ml} 5 \mathrm{~F}$ for $24 \mathrm{~h}$, and fixed with $70 \%$ ethanol (Beijing Chemical Reagent Factory, Beijing, China) at $-20^{\circ} \mathrm{C}$ overnight prior to staining with $100 \mu \mathrm{l} / \mathrm{ml}$ propidium iodide (PI) solution (Molecular Probes ${ }^{\circledR}$; Thermo Fisher Scientific, Waltham, MA, USA). Cell cycle distribution analysis was performed using a Coulter EPTCSXL 31240 flow cytometer, (Beckman Coulter, Inc., Brea, CA, USA).

Annexin V/PI staining. Cell apoptosis was detected using an Annexin V-fluorescein isothiocyanate (FITC)/PI apoptosis detection kit (Beyotime Institute of Biotechnology). The cells were treated with $0,5,10,20$ and $40 \mu \mathrm{g} / \mathrm{ml} 5 \mathrm{~F}$ for $24 \mathrm{~h}$, prior to harvesting. The cells were washed once with phosphate-buffered saline and resuspended in $500 \mu$ l binding buffer (both from Beyotime Institute of Biotechnology). Annexin V-FITC solution $(5 \mu \mathrm{l})$ and dissolved PI solution $(5 \mu \mathrm{l})$ were added to the cell suspensions. The samples were incubated for $15 \mathrm{~min}$ in the dark at room temperature, and immediately subjected to flow cytometric analysis. The The results were interpreted as follows: Lower left quadrant, Annexin V-FITC and PI negative cells; lower right quadrant, Annexin V-FITC positive cells in the early stage of apoptosis; upper left, dead PI positive cells; upper right Annexin V-FITC and PI positive cells in the late stage of apoptosis.

Caspase activity assay. Following incubation with $20 \mu \mathrm{g} / \mathrm{ml}$ $5 \mathrm{~F}$ for $24 \mathrm{~h}$, the enzymatic activities of caspase- 3 , caspase- 8 , and caspase- 9 were measured using commercially available caspase-3, -8 and -9 activity assay kits (Nanjing KeyGen Biotech, Co., Ltd., Nanjing, China) according to the manufacturer's protocols. The caspase activities were expressed as optical density $(\mathrm{OD})_{5 \mathrm{~F}} / \mathrm{OD}_{\text {control }}$.

Western blot analysis. Cells were lysed on ice in SDS Lysis Buffer (Beyotime Institute of Biotechnology), and supplemented with protease inhibitors and phosphatase inhibitor (Roche Diagnostics, Basel,Switzerland) and $1 \mathrm{mM}$ phenylmethylsulfonyl fluoride (Sigma-Aldrich). The protein concentration was determined using an Enhanced BCA Protein Assay Kit (Beyotime Institute of Biotechnology). Immunoblots of $50 \mu \mathrm{g}$ total protein were probed with primary antibodies overnight as follows: Rabbit anti-human polyclonal cyclin-dependent kinase inhibitor 1A (p21, Cip1) (p21; cat. no. BA0272; dilution, 1:200; Boster Bio-Engineering Ltd., Wuhan, China), rabbit anti-human polyclonal B-cell lymphoma 2 (Bcl-2; cat. no. ZS-492; dilution, 1:300; Zhongshan Golden Bridge Biotechnology, Co., Ltd., Beijing, China), mouse anti-mouse monoclonal Bcl-2-associated X protein (Bax; cat. no. ZS-7480; dilution, 1:300; Zhongshan Golden Bridge Biotechnology, Co., Ltd.), rabbit anti-human polyclonal nuclear factor $\kappa$-light-chain enhancer of activated B cells (NF- $\mathrm{KB}$ ) p65 phosphorylated
(p)-Ser ${ }^{536}$ (cat. no. 11014; dilution, 1:500; Signalway Antibody LLC., College Park, MD, USA), rabbit anti-human polyclonal nuclear factor of $\kappa$ light polypeptide gene enhancer in B-cells inhibitor $\alpha$ (I $\kappa \mathrm{B} \alpha$ ), rabbit anti-human polyclonal survivin (cat. no. sc-10811; dilution, 1:300; Santa Cruz Biotechnology, Inc., Santa Cruz, CA, USA) and $\beta$-actin (cat. no. sc-130656; dilution, 1:500; Santa Cruz Biotechnology, Inc.). Immunoblots were incubated with AP-labeled goat anti-mouse and goat anti-rabbit IgG (H+L) secondary antibodies (cat. nos. A0258 and A0239; dilution, 1:1,000; Beyotime Institute of Biotechnology) for $3 \mathrm{~h}$ at room temperature. Protein bands were visualized using chemiluminescent reagents (BeyoECL Plus; Beyotime Institute of Biotechnology, Haimen, China).

Xenograft tumor mouse model. Thirty female BALB/c mice (age, 6 weeks) were obtained from the Guangdong Medical College Experimental Animal Center (Zhanjiang, China) All mice were housed in plastic cages (5 mice/cage) and fed with standard rodent food and tap water. They were housed controlled conditions of humidity $(50 \pm 10 \%)$ and temperature $\left(23 \pm 2^{\circ} \mathrm{C}\right)$ on a 12:12-h light:dark cycle. Mice were subcutaneously inoculated with $2 \times 10^{6} \mathrm{C} 26$ cells in the left armpit region and randomly divided into three groups $(\mathrm{n}=10)$ as follows: Saline (control group), $50 \mathrm{mg} / \mathrm{kg} /$ day $5 \mathrm{~F}$ group, and $100 \mathrm{mg} / \mathrm{kg} /$ day $5 \mathrm{~F}$ group. The $5 \mathrm{~F}$ was dissolved in $0.85 \%$ normal saline. The following day, mice were intragastrically administered the specified doses. Their bodyweights were recorded twice each week. On day 14, all mice were sacrificed by cervical dislocation, and the tumor xenografts were removed and weighed. All animal experimental procedures were approved by the Guangdong Medical College Ethics Committee.

Inflammation-associated CRC mouse model. Thirty female ICR mice aged 6 weeks were obtained from Silaikejingda Experimental Animal Co., Ltd. (Changsha, China). Twenty mice were administered a single intraperitoneal injection of 1,2-dimethylhydrazine (DMH; $20 \mathrm{mg} / \mathrm{kg}$; Sigma-Aldrich). One week later, the mice were administered a course of $2 \%$ (w/v) dextran sodium sulfate (DSS; MP Biochenicals, Solon, $\mathrm{OH}, \mathrm{USA}$ ) in drinking water for one week. The 20 mice were divided into two equal groups $(\mathrm{n}=10)$ : The model and the $5 \mathrm{~F}$ $(50 \mathrm{mg} / \mathrm{kg} /$ day) group. Another 10 mice formed the control group. In the $5 \mathrm{~F}$ group, $5 \mathrm{~F}$ was intraperitoneally injected and administered for 35 consecutive days from the first day of the 18th week. In the model group, mice were intraperitoneally administered with normal saline. Assessment of general appearance, bodyweight, food uptake, rectal bleeding and stool consistency was performed every day. All the mice were sacrificed, and the blood and large bowel samples were collected. The number of tumors was counted by two independent observers blinded to the mouse treatment. The colons were fixed in $10 \%$ buffered formalin (Beijing Chemical Reagent Factory) for hematoxylin and eosin staining (Beijing Zhongshan Jinqiao Biotechnology Co., Ltd., Beijing, China).

Statistical analysis. Data are presented as means \pm standard deviation. The differences among the groups were analyzed with one-way analysis of variance using SPSS 13 software (SPSS, Inc., Chicago, IL, USA) and $\mathrm{P}<0.05$ was considered to indicate a statistically significant difference. 


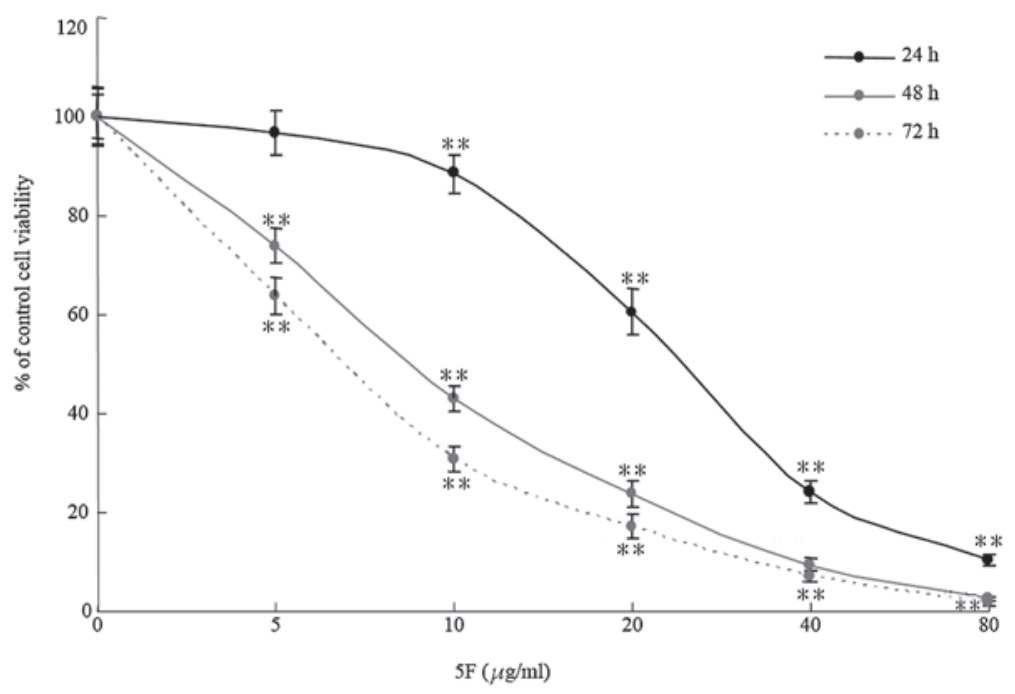

Figure 1. Cell viability was detected using the MTT assay following treatment with varying concentrations of $5 \mathrm{~F}$ for 24,48 or $72 \mathrm{~h}$. ${ }^{* *} \mathrm{P}<0.01 \mathrm{vs}$. the control. 5F, ent-11 $\alpha$-hydroxy-15-oxo-kaur-16-en-19-oic-acid.
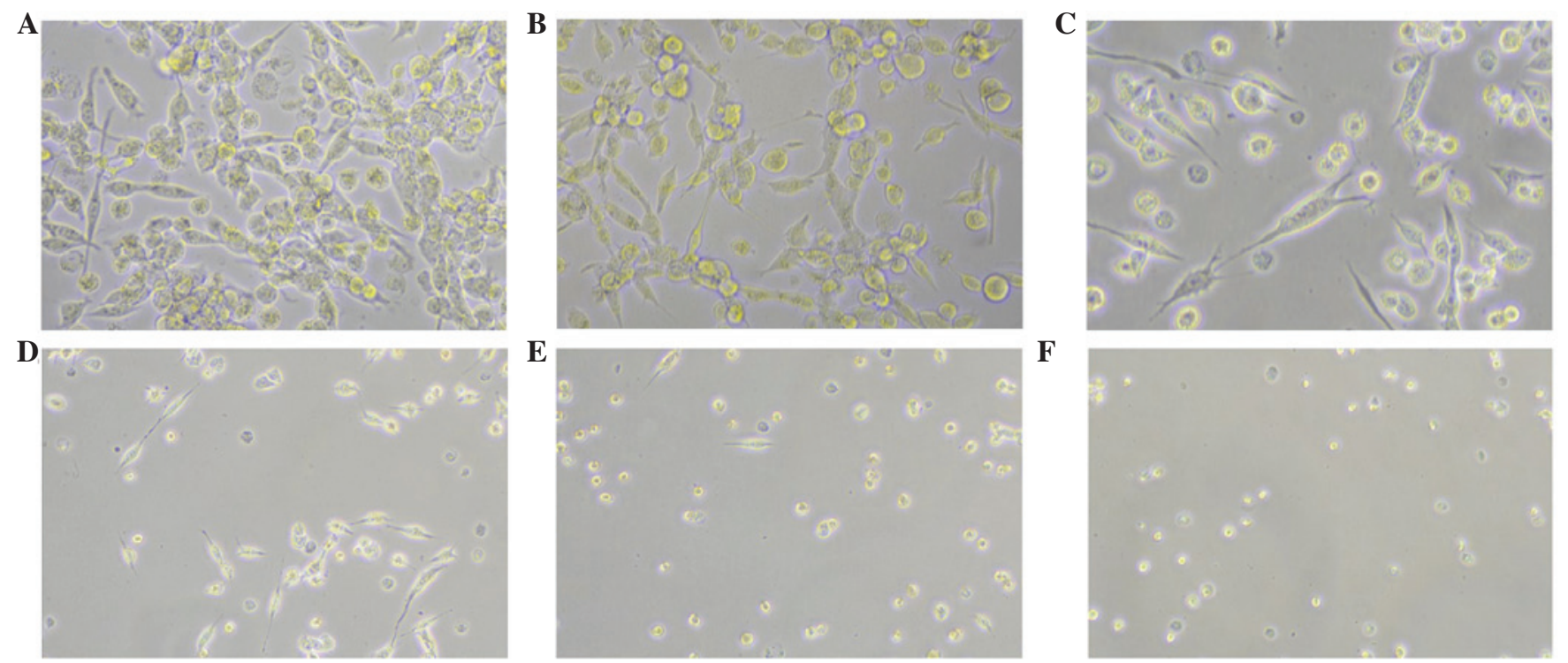

F

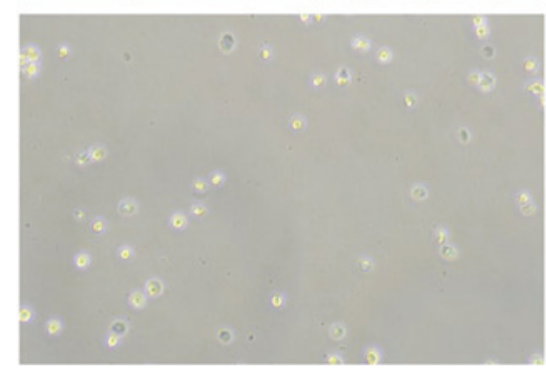

Figure 2. Cell morphology was observed at $24 \mathrm{~h}$ under an inverted phase contrast microscope (magnification, x200) following treatment with (A) 0 , (B) 5 , (C) 10, (D) 20, (E) 40 and (F) $80 \mu \mathrm{g} / \mathrm{ml}$ 5F. Cells treated with 5F became round and shrunken. 5F, ent-11 $\alpha$-hydroxy-15-oxo-kaur-16-en-19-oic-acid.

\section{Results}

5F-induced decrease in cell viability is dose- and time-dependent. To investigate whether $5 \mathrm{~F}$ prevents the proliferation and growth of CRC cells, C26 cells were treated with different concentrations of $5 \mathrm{~F}$ for 24,48 or $72 \mathrm{~h}$, and cell proliferation was detected using a standard MTT assay. $5 \mathrm{~F}$ treatment led to a time- and dose-dependent decrease in cell viability (Fig. 1). Furthermore, 5F-treated cells exhibited a rounded and granulated morphology, and were detached from the culture wall following a 24-h exposure (Fig. 2).

G2 block is involved in 5F-induced cell cycle arrest. To determine whether the 5F-induced reduction of cell viability was associated with changes in cell cycle distribution in CRC cells, the cell cycle phase in CRC cells incubated with 5F for
$24 \mathrm{~h}$ were analyzed. $5 \mathrm{~F}$ treatment arrested CRC cells in the $\mathrm{G}_{2}$ phase of the cell cycle in a dose-dependent manner, as compared with the control group $(\mathrm{P}<0.01)$ (Fig. 3).

$5 F$ induces cancer cell apoptosis. As $5 \mathrm{~F}$ treatment induced CRC cell cycle arrest in the $G_{2}$ phase of the cell cycle, the current study aimed to investigate whether $5 \mathrm{~F}$ induced CRC cell apoptosis. Data from the present study demonstrate that $5 \mathrm{~F}$ treatment for $24 \mathrm{~h}$ increased the percentage of apoptotic cells (Q2 + Q4; Fig. 4) in CRC cells in a dose-dependent manner, indicating that cell proliferation was inhibited by cell apoptosis (Fig. 4).

Mitochondria pathway is involved in 5F-induced apoptosis. To elucidate whether $5 \mathrm{~F}$ activates the caspase-dependent apoptosis signaling pathway, the catalytic activity of caspase-3, 

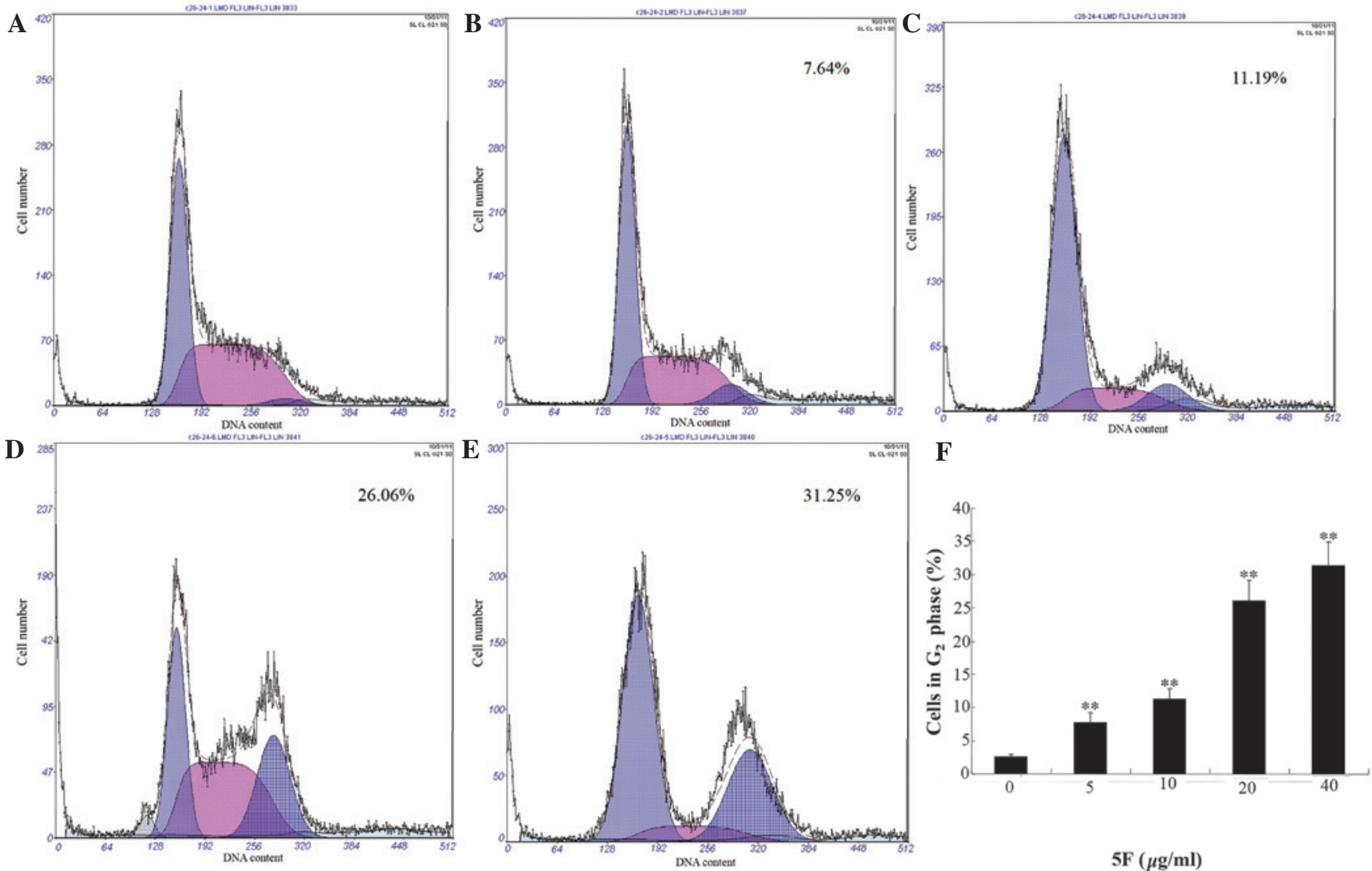

Figure 3. Effects of 5F on the cell cycle, as measured by flow cytometric analysis. Cells were treated with (A) 0 , (B) 5, (C) 10 , (D) 20 and (E) $40 \mu \mathrm{g} / \mathrm{ml} 5 \mathrm{~F}$ for 24 h. (F) Percentage of cells in the $\mathrm{G}_{2}$ phase. ${ }^{* *} \mathrm{P}<0.01$ vs. the control. 5F, ent-11 $\alpha$-hydroxy-15-oxo-kaur-16-en-19-oic-acid.

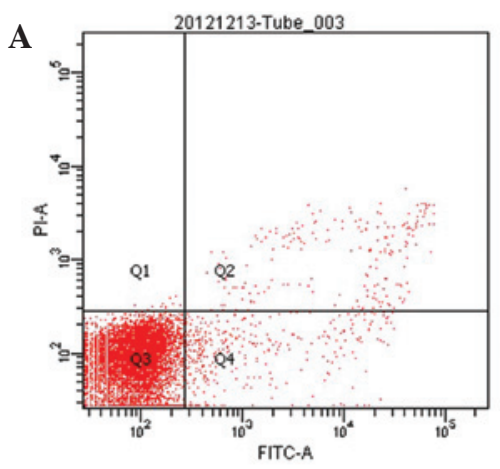

D

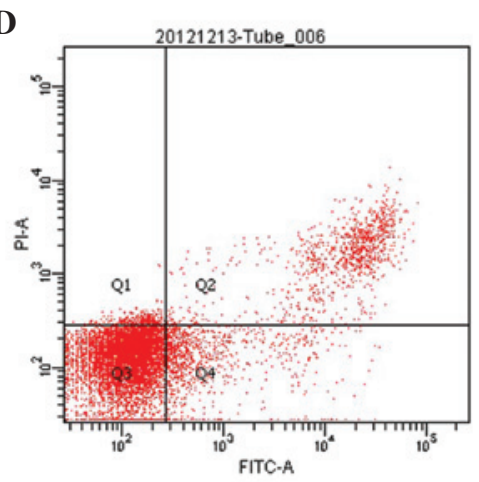

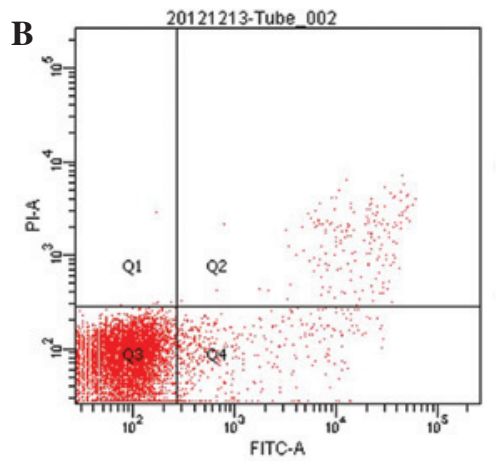
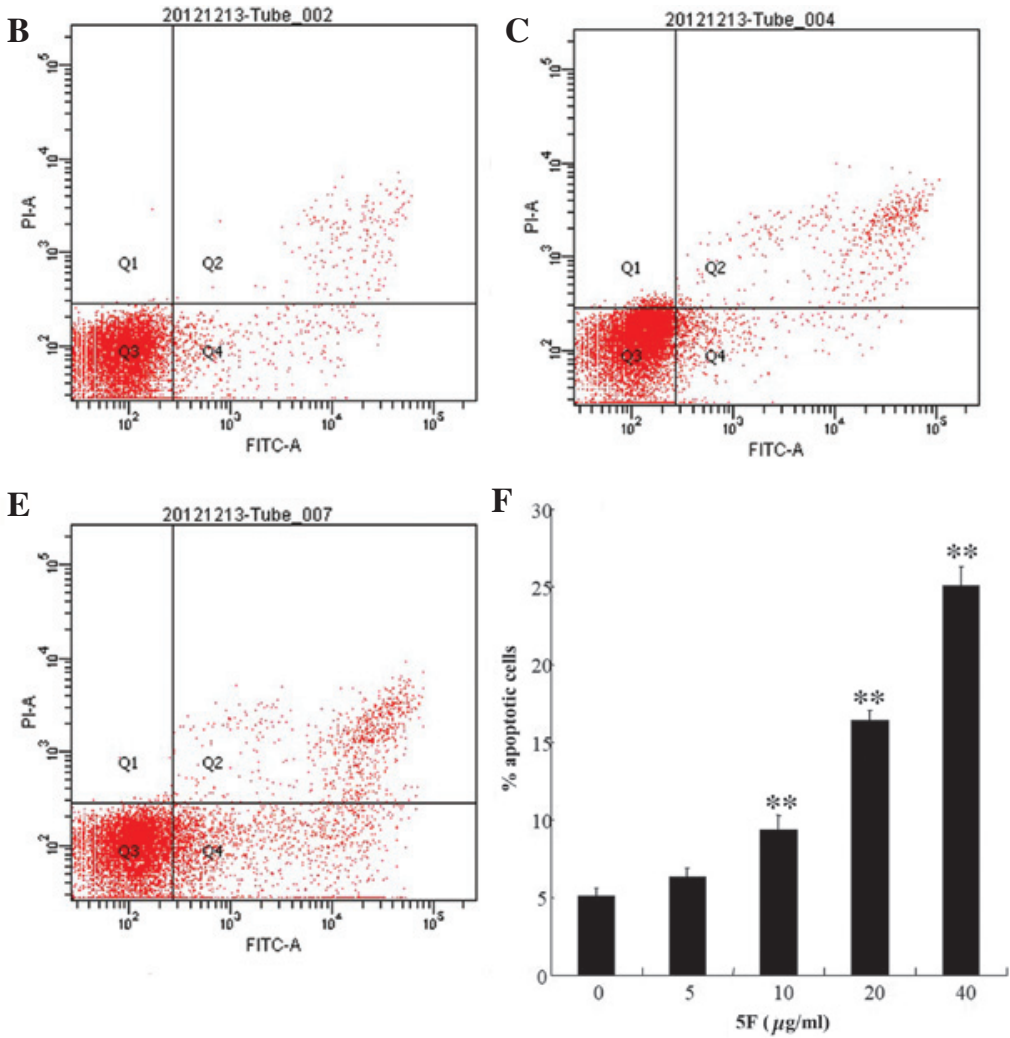

Figure 4. Effects of 5F on cell apoptosis analyzed by flow cytometry. (A) 0, (B) 5, (C) 10, (D) 20 and (E) $40 \mu \mathrm{g} / \mathrm{ml} 5 \mathrm{~F}$ treatment increased the percentages of Annexin- $\mathrm{V}^{+} / \mathrm{PI}$ and Annexin- $\mathrm{V}^{+} / \mathrm{PI}^{+}$cells. (F) The data indicated a dose-dependent induction of cell apoptosis at $24 \mathrm{~h}$. Q1, PI positive dead cells; Q2, Annexin V-FITC and PI positive late apoptotic cells; Q3, Annexin V-FITC and PI negative cells living cells; Q4, Annexin V-FITC positive early apoptotic cells. ${ }^{* *}$ P $<0.01$ vs. the control. 5F, ent-11 $\alpha$-hydroxy-15-oxo-kaur-16-en-19-oic-acid; FITC, fluorescein isothiocyanate; PI, propidium iodide. 


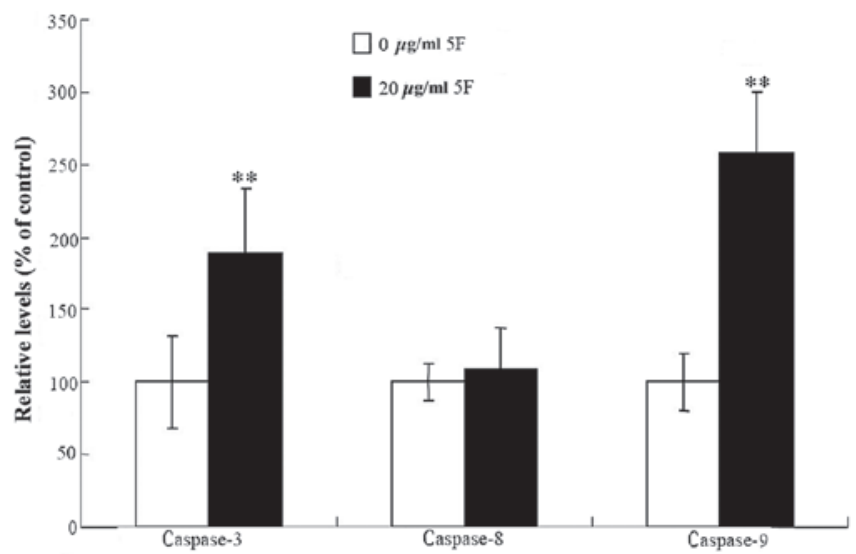

Figure 5. 5F affected the enzymatic activities of caspase-3, caspase- 8 and caspase-9 in C26 cells. Following incubation with $20 \mu \mathrm{g} / \mathrm{ml} 5 \mathrm{~F}$ for $24 \mathrm{~h}$, the enzymatic activities of caspase- 3 , caspase-8, and caspase- 9 were analyzed by comparison with the control. ${ }^{* *} \mathrm{P}<0.01$ vs. the control. $5 \mathrm{~F}$, ent-11 $\alpha$-hydroxy-15-oxo-kaur-16-en-19-oic-acid.

caspase- 8 and caspase- 9 was evaluated in CRC cells. The results demonstrate that $5 \mathrm{~F}$ significantly increased the activity of caspase-3 and caspase-9, however only marginally affected the activity of caspase-8 (Fig. 5), suggesting that 5F-induced apoptosis was mediated by the mitochondrial signaling pathway, but not the death-receptor signaling pathway.

$5 F$ alters the expression levels of $p 21, B c l-2, B a x, N F-\kappa B, I \kappa B \alpha$ and survivin proteins. To elucidate the underlying mechanism of 5F-induced apoptosis in $\mathrm{C} 26$ cells, the protein levels of $\mathrm{p} 21$, $\mathrm{Bcl}-2, \mathrm{Bax}, \mathrm{NF}-\kappa \mathrm{B}, \mathrm{I} \kappa \mathrm{B} \alpha$ and survivin (which are involved in cell cycle progression, growth and apoptosis) were measured. The treatment of $\mathrm{C} 26$ cells with $5 \mathrm{~F}$ resulted in the significant upregulation of $\mathrm{p} 21$, Bax, $\mathrm{I} \kappa \mathrm{B} \alpha$ and downregulation of $\mathrm{Bcl}-2$, $\mathrm{NF}-\kappa \mathrm{B}$ and survivin $(\mathrm{P}<0.01)($ Fig. 6$)$, suggesting that $5 \mathrm{~F}$ induces cell apoptosis.

$5 F$ inhibits tumor growth in a xenograft tumor mouse model. The xenograft tumor mouse model (induced by $\mathrm{C} 26$ cells) was successfully established and it was observed that $5 \mathrm{~F}$ inhibited the tumor growth. Compared with the mean tumor weight of $1.29 \pm 0.22 \mathrm{~g}$ in the model group, the mean tumor weights of the 50 and $100 \mathrm{mg} / \mathrm{kg} /$ day $5 \mathrm{~F}$ groups were $0.76 \pm 0.19$ and $0.45 \pm 0.28 \mathrm{~g}$, respectively (Fig. 7). However, there were no significant differences identified in bodyweight, food and water intake or activity between the groups.

Antineoplastic effect of $5 F$ in the inflammation-associated CRC mouse model. General observations were performed on each mouse. Three mice in the model group exhibited rectocele 13,15 and 16 weeks after commencing the experiment, and 1 mouse in the $5 \mathrm{~F}$-treated group exhibited rectocele 14 weeks after commencing the experiment. The colorectal tumors detected in the CRC model group (induced by DMH/DSS) were identified to be well-differentiated tubular adenocarcinoma and $5 \mathrm{~F}$ treatment improved the tumor pathology (Fig. 8). The number of tumors was significantly decreased in the $5 \mathrm{~F}$ group compared with that of the model group $(\mathrm{P}<0.01)$, suggesting that $5 \mathrm{~F}$ significantly inhibits tumorigenesis (Fig. 9A).

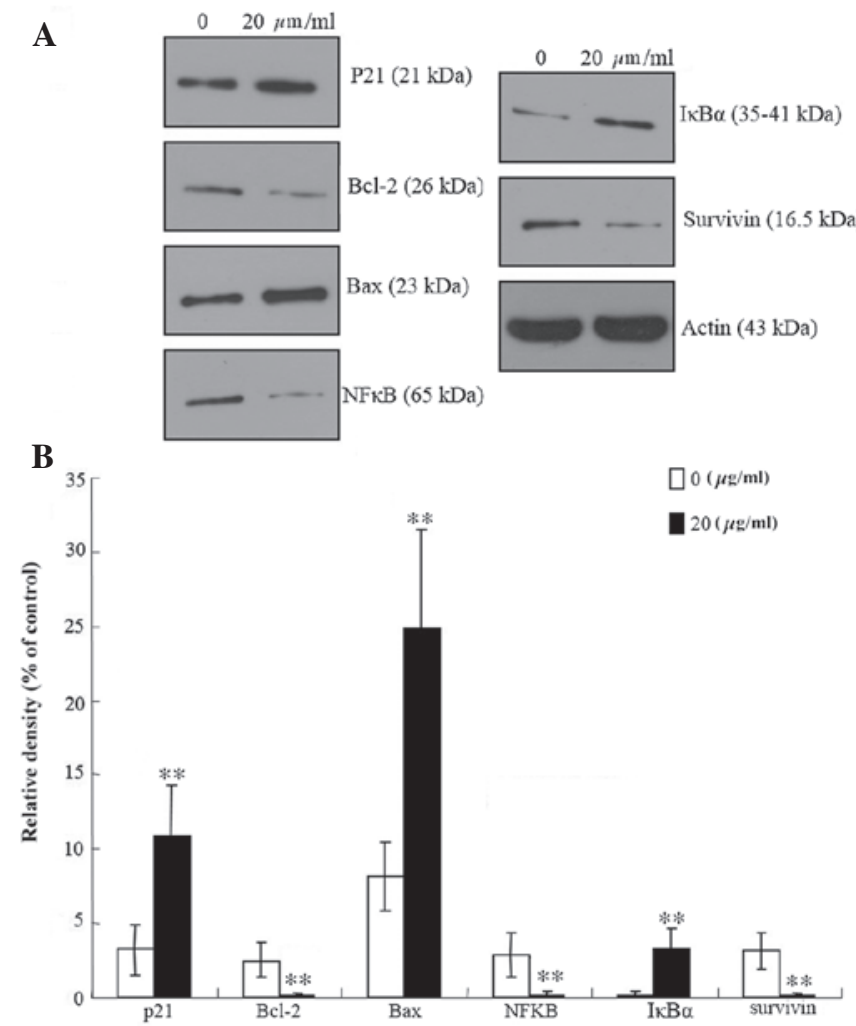

Figure 6. Effect of $5 \mathrm{~F}$ treatment on the cell cycle, apoptosis and growth-associated proteins. Cells were treated with $20 \mu \mathrm{g} / \mathrm{ml} 5 \mathrm{~F}$ for $24 \mathrm{~h}$. (A) Western blots and (B) the relative density of $\mathrm{p} 21, \mathrm{Bcl}-2$, Bax, NF- $\mathrm{kB}$ p65, ІкB, survivin and $\beta$-actin. ${ }^{* *} \mathrm{P}<0.01$ vs. the control. $5 \mathrm{~F}$, ent-11 $\alpha$-hydroxy-15-oxo -kaur-16-en-19-oic-acid; p21, cyclin-dependent kinase inhibitor 1A; Bcl-2, B-cell CLL/lymphoma 2; Bax, Bcl-2-associated X protein; NFkB, nuclear factor- $\kappa$-light-chain enhancer of activated $\mathrm{B}$ cells; I $\mathrm{I} \mathrm{B} \alpha$, nuclear factor of $\kappa$ light polypeptide gene enhancer in B-cells inhibitor, $\alpha$.

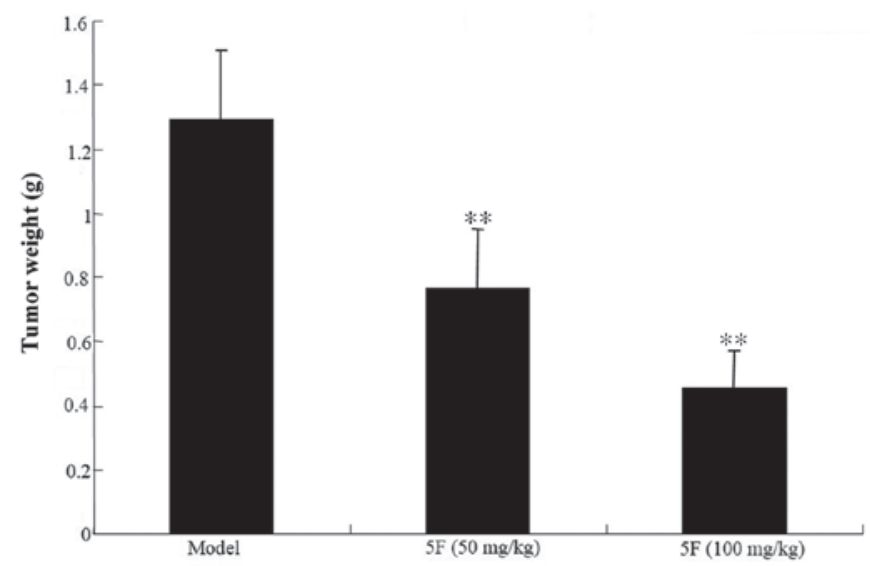

Figure 7. Weights of xenograft tumor model and 5F-treated tumors. ${ }^{*} \mathrm{P}<0.05$, ${ }^{* * *} \mathrm{P}<0.01$ vs. the control. $5 \mathrm{~F}$, ent-11 $\alpha$-hydroxy-15-oxo-kaur-16-en-19-oic-acid.

$5 F$ treatment did not result in major side effects in the inflammation-associated CRC mouse model. The side effects of 5F were investigated in three parts as follows: i) Physiological observations demonstrated no significant weight loss, no reduction in activity levels and no instances of self-torture, self isolation or mortality were observed; ii) liver function tests indicated that the levels of alanine transaminase (ALT) in the model and 5F groups were higher than in the control 
A

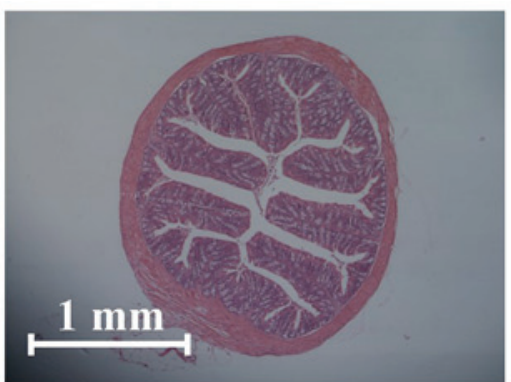

D

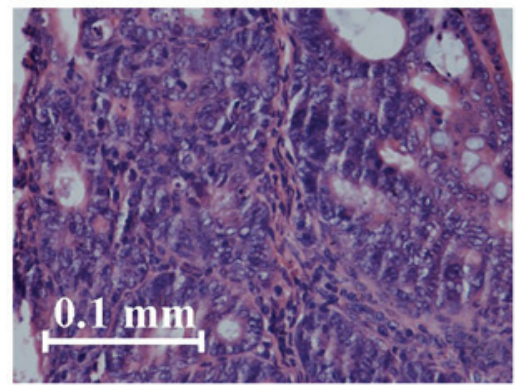

B

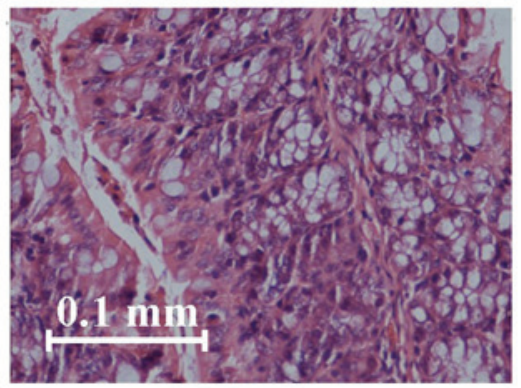

$\mathbf{E}$

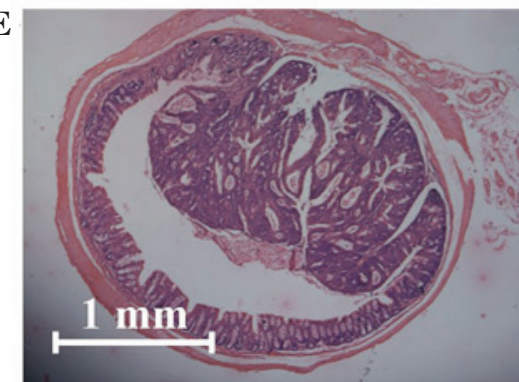

C

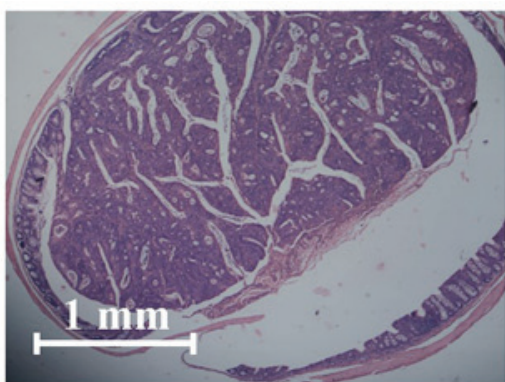

F

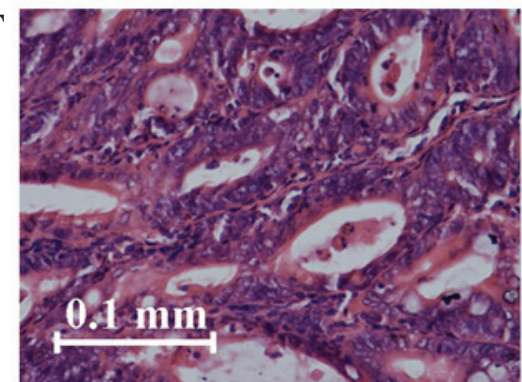

Figure 8. Hematoxylin and eosin staining of colon sections in mice from (A and B) the control group treated with saline, $(\mathrm{C}$ and $\mathrm{D})$ the model group treated with DMH/DSS, and (E and F) the 5F group treated with DMH/DSS and 5F. 5F, ent-11 $\alpha$-hydroxy-15-oxo-kaur-16-en-19-oic-acid; DMH, 1,2-dimethylhydrazine; DSS, dextran sodium sulfate.

A

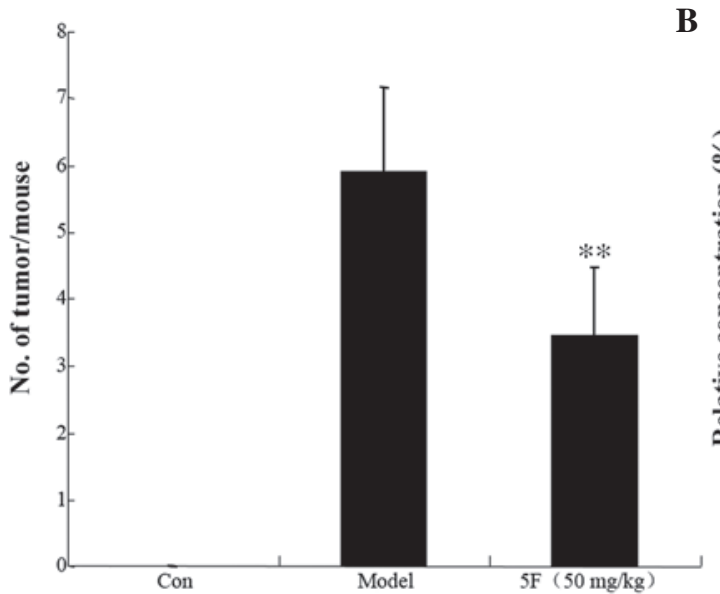

B

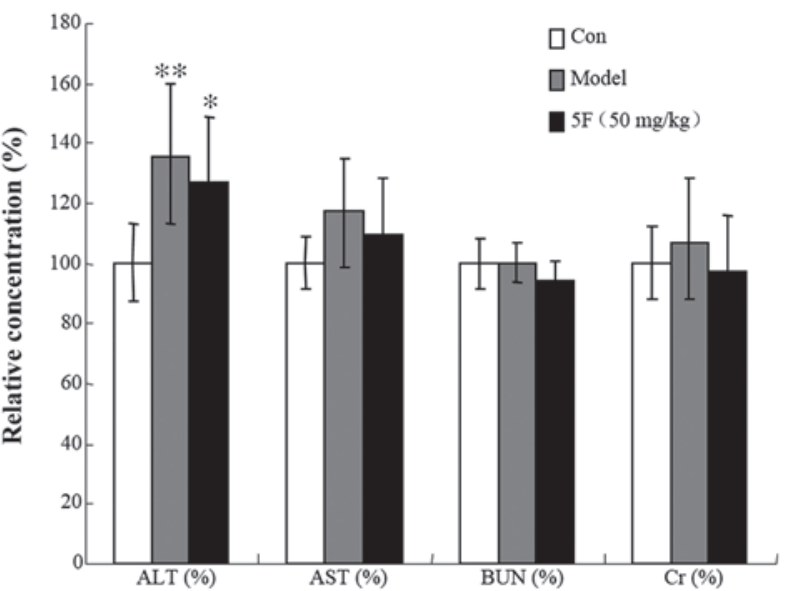

Figure 9. Tumor number and biochemical parameters in the inflammation-associated colon cancer mouse model. (A) The tumor number in 1,2-dimethylhydrazine/dextran sodium sulfate-treated mice (model) and $5 \mathrm{~F}$-treated mice. (B) The effect of $5 \mathrm{~F}$ treatment on liver and renal function of mice. ${ }^{*} \mathrm{P}<0.05,{ }^{* *} \mathrm{P}<0.01$ vs. the control. Con, control; 5F, ent-11 $\alpha$-hydroxy-15-oxo-kaur-16-en-19-oic-acid; ALT, alanine transaminase; AST, aspartate transaminase; BUN, blood urea nitrogen; $\mathrm{Cr}$, creatinine.

group, and highest in the CRC model group; iii) renal function analysis identified no difference in the levels of blood urea nitrogen (BUN) or creatinine (Cr) among all of the groups. Therefore, biochemical parameters and physiological observations indicate that $5 \mathrm{~F}$ treatment did not result in serious side effects (Fig. 9B).

\section{Discussion}

In the present study, $5 \mathrm{~F}$ has been demonstrated to elicit a growth inhibitory effect on CRC cells, in a xenograft tumor mouse model and in a DMH/DSS-induced tumor mouse model, suggesting that $5 \mathrm{~F}$ may be administered to treat $\mathrm{CRC}$.

Deregulation of the cell cycle and evasion of apoptosis are characteristic of cancer cells (12). Thus, inhibition of cell cycle progression and/or induction of apoptosis is considered to be particularly useful in the treatment of cancer. Previously, 5F has been demonstrated to arrest CNE-2Z, A549 and FRO cells at the $G_{2}$ phase $(3,4,6)$. Consistent with these studies, the current study demonstrated that $5 \mathrm{~F}$ induced $\mathrm{G}_{2}$-phase arrest in $\mathrm{CRC}$ cells. The p21 protein is an inhibitor of cyclin-dependent kinases (CDKs) and is key in the arrest of cells at the $G_{2} / M$ transition $(13,14)$. Various studies have demonstrated that anticancer therapeutic agents increase the number of cells in the $\mathrm{G}_{2} / \mathrm{M}$ cell cycle phases, which is accompanied by upregulation of p21 (15-20). The present study demonstrated that $5 \mathrm{~F}$ increased the expression level of p21 in CRC cells. Apoptosis is important in various normal processes, from fetal development to adult tissue homeostasis, as it eliminates cells that have completed their life cycle, have become ineffective 
or are harmful to the organism (21). Apoptosis is induced via the extrinsic (death-receptor) or the intrinsic (mitochondrial) signaling pathways. The intrinsic signaling pathway induces the release of cytochrome $c$ from the mitochondria and activates caspase-9. Activated caspase- 9 subsequently activates caspase-3, which further cleaves poly (ADP-ribose) polymerase 1 resulting in apoptosis. The extrinsic signaling pathway is triggered by a death ligand binding to a death receptor, which activates caspase-8, further activating caspase-3 directly or activating the intrinsic signaling pathway, which also affects caspase-3 (22-24). The Bcl-2 family regulate the mitochondrial outer membrane permeabilization pore and an elevated ratio of $\mathrm{Bax} / \mathrm{Bcl}-2$ is observed in apoptosis of cancer cells (19,25-29). In the present study, 5F markedly increased the percentage of Annexin V/FITC-positive CRC cells, the $\mathrm{Bax} / \mathrm{Bcl} 2$ ratio and the activity of caspase- 3 and caspase-9, however, it did not alter the activity of caspase-8. This suggests that 5F-induced apoptosis in CRC cells was mediated by the mitochondrial signaling pathway and not the death-receptor signaling pathway.

$\mathrm{NF}-\kappa \mathrm{B}$ is an important mediator of cell cycle progression and cell survival associated with carcinogenesis (30). Under basal conditions, $N F-\kappa \mathrm{B}$ is present in the cytoplasm and binds to $\mathrm{I} \kappa \mathrm{B}$. Phosphorylation of I $\mathrm{B}$ by $\mathrm{I} \kappa \mathrm{B}$ kinase results in ubiquitination and degradation of $\mathrm{I} \kappa \mathrm{B}$. Subsequently, NF- $\mathrm{B}$ is translocated to the nucleus, where $N F-\kappa B$ regulates the transcription of a number of genes involved in tumorigenesis and cell growth $(30,31) . N F-\kappa B$ has been recognized as key in the initiation and progression of CRC (32). Therefore, $N F-\kappa B$ may be a potential therapeutic target in CRC. Results from the present study demonstrated that treatment of CRC cells with $5 \mathrm{~F}$ inhibited the expression of NF- $\kappa \mathrm{B}$ and degradation of $\mathrm{I} \kappa \mathrm{B} \alpha$, suggesting that the effects of $5 \mathrm{~F}$ on $\mathrm{NF}-\kappa \mathrm{B}$ may be influenced by inhibition of phosphorylation and the subsequent proteolysis of $\mathrm{I} \kappa \mathrm{B} \alpha$. Survivin is the smallest member of the family of inhibitors of apoptosis proteins (IAPs) (33). It is overexpressed in the majority of human tumors, and upregulation of survivin has been associated with poor prognosis in patients with tumors, thus, survivin has been proposed as a potential target for anticancer intervention $(34,35)$. In the present study, the effects of $5 \mathrm{~F}$ on survivin were investigated and it was observed that $5 \mathrm{~F}$ treatment resulted in a decreased expression level of survivin.

In in vivo experiments, the tumoricidal effect, as well as the side effects of 5F were investigated in two CRC mouse models. Results of the current study indicated that $5 \mathrm{~F}$ reduced the weight of xenograft tumors and the number of DMH/DSS-induced CRC tumors. Liver and kidney damage are critical and frequent side effects generated by antitumor agents. Therefore, aspartate transaminase (AST), ALT, Cr and BUN were measured to determine the side effects of 5F $(36,37)$. No difference in the levels of AST, Cr and BUN was observed among all the three groups; however, the levels of ALT in the model and 5F groups were higher than those in the control group. Notably, the level of ALT was the highest in the model group, thus the DMH/DSS treatment may have resulted in the rise of $\mathrm{ALT}$, rather than $5 \mathrm{~F}$.

In conclusion, $5 \mathrm{~F}$ has been demonstrated as an effective therapeutic agent against $\mathrm{CRC}$ with minimal side effects. The underlying mechanism may be induction of apoptosis via the mitochondrial signaling pathway, suggesting that $5 \mathrm{~F}$ may be administered as a potential anticancer therapeutic agent in clinical practice.

\section{Acknowledgements}

The present study was supported by the National Natural Science Foundation of China (grant nos. 81173240 and 3987099), the Natural Science Foundation of Guangdong Province (grant no. 2014A030307001), the Science and Technology Fund of Guangdong (grant no. 2011B031700065), the Science and Technology Fund of Zhanjiang (grant no. 2014A01014) and the Fund of Guangdong Medical College (grant nos. Z2013001 and B2013019).

\section{References}

1. Jemal A, Bray F, Center MM, Ferlay J, Ward E and Forman D: Global cancer statistics. CA Cancer J Clin 61: 69-90, 2011.

2. Chen W, Zheng R, Zhang S, Zhao P, Zeng H, Zou X and He J: Annual report on status of cancer in China, 2010. Chin J Cancer Res 26: 48-58, 2014

3. Wu K, Liu Y, Lv Y, Cui L, Li W, Chen J, Liang NC and Li L: Ent-11 $\alpha$-hydroxy-15-oxo-kaur-16-en-19-oic-acid induces apoptosis and cell cycle arrest in CNE-2Z nasopharyngeal carcinoma cells. Oncol Rep 29: 2101-2108, 2013.

4. Li L, Chen GG, Lu YN, Liu Y, Wu KF, Gong XL, Gou ZP, Li MY and Liang NC: Ent-11 $\alpha$-Hydroxy-15-oxo-kaur-16-en-19-oic-acid Inhibits Growth of Human Lung Cancer A549 Cells by Arresting Cell Cycle and Triggering Apoptosis. Chin J Cancer Res 24: 109-115, 2012.

5. Vlantis AC, Lo CS, Chen GG, Ci Liang N, Lui VW, Wu K, Deng YF, Gong X, Lu Y, Tong MC and van Hasselt CA: Induction of laryngeal cancer cell death by Ent-11-hydroxy-15-oxo-kaur-16-e n-19-oic acid. Head Neck 32: 1506-1518, 2010.

6. Liu ZM, Chen GG, Vlantis AC, Liang NC, Deng YF and van Hasselt CA: Cell death induced by ent-11alpha-hydroxy-15-o xo-kaur-16-en-19-oic-acid in anaplastic thyroid carcinoma cells is via a mitochondrial-mediated pathway. Apoptosis 10: 1345-1356, 2005.

7. Liu Z, Ng EK, Liang NC, Deng YF, Leung BC and Chen GG: Cell death induced by Pteris semipinnata L. is associated with p53 and oxidant stress in gastric cancer cells. FEBS Lett 579: 1477-1487, 2005.

8. Chen GG, Liang NC, Lee JF, Chan UP, Wang SH, Leung BC and Leung KL: Over-expression of Bcl-2 against Pteris semipinnata L-induced apoptosis of human colon cancer cells via a NF-kappa B-related pathway. Apoptosis 9: 619-627, 2004.

9. Chen GG, Leung J, Liang NC, Li L, Wu K, Chan UP, Leung BC, Li M, Du J, Deng YF, et al: Ent-11alpha-hydroxy-15-oxo-kaur-16 -en-19-oic-acid inhibits hepatocellular carcinoma in vitro and in vivo via stabilizing IkB $\alpha$. Invest New Drugs 30: 2210-2218, 2012.

10. Li MY, Leung J, Kong AW, Liang NC, Wu K, Hsin MK, Deng YF, Gong X, Lv Y, Mok TS, et al: Anticancer efficacy of $5 \mathrm{~F}$ in NNK-induced lung cancer development of $\mathrm{A} / \mathrm{J}$ mice and human lung cancer cells. J Mol Med (Berl) 88: 1265-1276, 2010.

11. Deng YF and Liang N: Study on extraction and separation of diterpenoids from Pteris semipinnata. Chinese Pharmaceutical Journal 39: 742-744, 2004 [In Chinese].

12. Senderowicz AM: Targeting cell cycle and apoptosis for the treatment of human malignancies. Curr Opin Cell Biol 16: 670-678, 2004.

13. Cazzalini O, Scovassi AI, Savio M, Stivala LA and Prosperi E: Multiple roles of the cell cycle inhibitor p21(CDKN1A) in the DNA damage response. Mutat Res 704: 12-20, 2010.

14. Taylor WR and Stark GR: Regulation of the G2/M transition by p53. Oncogene 20: 1803-1815, 2001.

15. Cho JH, Lee JG, Yang YI, Kim JH, Ahn JH, Baek NI, Lee KT and Choi JH: Eupatilin, a dietary flavonoid, induces G2/M cell cycle arrest in human endometrial cancer cells. Food Chem Toxicol 49: 1737-1744, 2011.

16. Castro J, Ribó M, Navarro S, Nogués MV, Vilanova M and Benito A: A human ribonuclease induces apoptosis associated with p21WAF1/CIP1 induction and JNK inactivation. BMC Cancer 11: 9, 2011. 
17. Kalimutho M, Minutolo A, Grelli S, Formosa A, Sancesario G, Valentini A, Federici G and Bernardini S: Satraplatin (JM-216) mediates $\mathrm{G} 2 / \mathrm{M}$ cell cycle arrest and potentiates apoptosis via multiple death pathways in colorectal cancer cells thus overcoming platinum chemo-resistance. Cancer Chemother Pharmacol 67: 1299-1312, 2011.

18. Huang WW, Ko SW, Tsai HY, Chung JG, Chiang JH, Chen KT, Chen YC, Chen HY, Chen YF and Yang JS: Cantharidin induces G2/M phase arrest and apoptosis in human colorectal cancer colo 205 cells through inhibition of CDK1 activity and caspase-dependent signaling pathways. Int J Oncol 38: 1067-1073, 2011.

19. Dia VP and Mejia EG: Lunasin promotes apoptosis in human colon cancer cells by mitochondrial pathway activation and induction of nuclear clusterin expression. Cancer Lett 295: 44-53, 2010.

20. Chu G: Cellular responses to cisplatin. The roles of DNA-binding proteins and DNA repair. J Biol Chem 269: 787-790, 1994.

21. Cotter TG. Apoptosis and cancer: the genesis of a research field. Nat Rev Cancer 9: 501-507, 2009.

22. Mcllwain DR, Berger T and Mak TW: Caspase functions in cell death and disease. Cold Spring Harb Perspect Biol 5: a008656, 2013

23. Elmore S: Apoptosis: A review of programmed cell death. Toxicol Pathol 35: 495-516, 2007.

24. Slee EA, Adrain C and Martin SJ: Executioner caspase-3, -6, and -7 perform distinct, non-redundant roles during the demolition phase of apoptosis. J Biol Chem 276: 7320-7326, 2001.

25. Arora R, Yates C, Gary BD, McClellan S, Tan M, Xi Y, Reed E, Piazza GA, Owen LB and Dean-Colomb W: Panepoxydone targets NF-kB and FOXM1 to inhibit proliferation, induce apoptosis and reverse epithelial to mesenchymal transition in breast cancer. PLoS One 9: e98370, 2014

26. Queiroz EA, Puukila S, Eichler R, Sampaio SC, Forsyth HL, Lees SJ, Barbosa AM, Dekker RF, Fortes ZB and Khaper N: Metformin induces apoptosis and cell cycle arrest mediated by oxidative stress, AMPK and FOXO3a in MCF-7 breast cancer cells. PLoS One 9: e98207, 2014.
27. Huang M, Tang SN, Upadhyay G, Marsh JL, Jackman CP, Shankar S and Srivastava RK: Embelin suppresses growth of human pancreatic cancer xenografts, and pancreatic cancer cells isolated from KrasG12D mice by inhibiting Akt and Sonic hedgehog pathways. PLoS One 9: e92161, 2014.

28. Lin JP, Yang JS, Lee JH, Hsieh WT and Chung JG: Berberine induces cell cycle arrest and apoptosis in human gastric carcinoma SNU-5 cell line. World J Gastroenterol 12: 21-28, 2006.

29. Hwang JM, Kuo HC, Tseng TH, Liu JY and Chu CY: Berberine induces apoptosis through a mitochondria/caspases pathway in human hepatoma cells. Arch Toxicol 80: 62-73, 2006.

30. Aggarwal BB: Nuclear factor-kappaB: The enemy within. Cancer Cell 6: 203-208, 2004.

31. Gupta S, Hastak K, Afaq F, Ahmad N and Mukhtar H: Essential role of caspases in epigallocatechin-3-gallate-mediated inhibition of nuclear factor kappa B and induction of apoptosis. Oncogene 23: 2507-2522, 2004

32. Vaiopoulos AG, Athanasoula KC and Papavassiliou AG: NF-KB in colorectal cancer. J Mol Med-Berl 91: 1029-1037, 2013.

33. Srinivasula SM and Ashwell JD: IAPs: What's in a name? Mol Cell 30: 123-135, 2008

34. Cheung CH, Huang CC, Tsai FY, Lee JY, Cheng SM, Chang YC, Huang YC, Chen SH and Chang JY: Survivin - biology and potential as a therapeutic target in oncology. Onco Targets Ther 6: 1453-1462, 2013.

35. Altieri DC: Targeting survivin in cancer. Cancer Lett 332: 225-228, 2013

36. Gracias VH and McGonigal MD: Monitoring organ function. Heart, liver, and kidney. Surg Clin North Am 80: 911-919, 2000.

37. Yao Y, Chen F, Wang M, Wang J and Ren G: Antidiabetic activity of Mung bean extracts in diabetic KK-Ay mice. J Agric Food Chem 56: 8869-8873, 2008 